\title{
High survival in young patients using a second generation uncemented total hip replacement
}

\author{
Marcus R. Streit • Kerstin Schröder • Matthias Körber • \\ Christian Merle • Tobias Gotterbarm • \\ Volker Ewerbeck • Peter R. Aldinger
}

Received: 25 September 2011 / Accepted: 15 October 2011 /Published online: 24 November 2011

(C) The Author(s) 2011. This article is published with open access at Springerlink.com

\begin{abstract}
Purpose Whilst excellent long-term results with contemporary uncemented stems have been reported for total hip arthroplasty in young patients, the survival rates for the whole reconstruction are often compromised by high failure rates on the acetabular site due to peri-acetabular osteolysis and accelerated wear.

Methods In patients 60 years old or younger, we retrospectively reviewed the results at a minimum of ten years of 89 consecutive uncemented total hip replacements in 88 patients using the press-fit Fitmore acetabular component in combination with the CLS Spotorno stem and a 28-mm Metasul metal-on-metal articulation or a $28-\mathrm{mm}$ alumina ceramic on conventional polyethylene bearing. The mean age at the time of surgery was 49 years (range, 25-60). The mean clinical and radiological follow-up was 12 years (range, 10-15).
\end{abstract}

\footnotetext{
M. R. Streit $(\bowtie) \cdot$ M. Körber $\cdot$ C. Merle $\cdot$ T. Gotterbarm $•$

V. Ewerbeck

Department of Orthopaedic and Trauma Surgery,

University of Heidelberg,

Schlierbacher Landstrasse 200a,

69118 Heidelberg, Germany

e-mail: marcus.streit@arcor.de

M. R. Streit

e-mail: marcus.streit@med.uni-heidelberg.de

K. Schröder

Department of Orthopaedic Surgery, University of Frankfurt,

Marienburgstr. 2,

60528 Frankfurt, Germany

\section{P. R. Aldinger}

Department of Orthopaedic and Trauma Surgery,

Orthopädische Klinik Paulinenhilfe, Diakonieklinikum,

Rosenbergstrasse 38,

70192 Stuttgart, Germany
}

Results Six patients (six hips) died and two patients (two hips) were lost to follow-up. Five hips were revised: one for deep infection, one for peri-prosthetic femoral fracture, and one for aseptic stem loosening. In two hips an isolated revision of the acetabular liner was performed (one for recurrent dislocation and one for unexplained pain). No revision was performed for accelerated wear, osteolysis or aseptic loosening of the acetabular shell. We could not detect peri-acetabular osteolysis visible on plain radiographs in those hips evaluated radiographically. The Kaplan-Meier survival with revision for any reason as the endpoint was $94 \%$ (95\% confidence interval, $86-97)$ at 12 years.

Conclusions The survival rates and the radiological outcomes with this implant combination in this young and active patient group are encouraging when compared to the results reported for other uncemented cups in this age group.

\section{Introduction}

One of the most challenging problems in total hip arthroplasty (THA) remains the management of the young patient. Good and excellent long-term survival rates for contemporary uncemented femoral components have been reported [1-4], even in young patients [5]. There is evidence in the current literature that the acetabular site is critical in uncemented THA, especially in young patients [6-8]. Despite encouraging long-term fixation of the metallic shell [9], long-term survival of uncemented cups is frequently compromised by excessive liner wear and peri-acetabular osteolysis $[6,7,10]$, particularly in young and active patients $[7,9,11,12]$.

We report the results at 12 years of an independent series using a contemporary uncemented modular titanium pressfit cup in combination with a long-term proven contempo- 
rary uncemented femoral component $[2,5]$ in a cohort of young and active patients.

\section{Patients and methods}

This clinical and radiological study comprises 89 consecutive total hip replacements (THR) in 88 patients who were 60 years old or younger at the time of surgery using the uncemented Fitmore press-fit acetabular component (Zimmer, Winterthur, Switzerland) in combination with the CLS Spotorno stem (Zimmer, Winterthur, Switzerland). All operations were performed at the same institution in a multi-surgeon series between April 1994 and December 1997. Patient demographics and diagnoses are listed in Tables 1 and 2. The clinical scores were recorded prospectively and the data were reviewed retrospectively at a minimum of ten years postoperatively. Informed consent was obtained from all patients. Procedures followed were approved by the institutional review board of the University of Heidelberg and the study was conducted in accordance with the Helsinki Declaration of 1975, as revised in 2000.

The Fitmore acetabular component (Fig. 1) is a modular press-fit cup with a metal backing made of Ti-6Al-4V alloy. A four-layer mesh made from Protasul-Ti (chemically pure titanium, Sulmesh, Zimmer, Winterthur, Switzerland) is welded to the metal back. The grit-blasted Protasul-Ti wire mesh provides a regular porous structure $(65 \%$ porosity, average pore size $400-640 \mu \mathrm{m}$, surface roughness $\mathrm{R}_{\mathrm{a}}=$ $5 \mu \mathrm{m})$, to promote osseo-integration. The metal back has a thickness of $2.5 \mathrm{~mm}$ independent of the size, and the thickness of the sulmesh coating is $1.6 \mathrm{~mm}$. The prosthesis has an eccentric biradial design with a hemispherical periphery and a flattened polar region to achieve primary stability intrinsically by wedging an oversized, externally aspherical cup into a smaller (underreamed) hemispherical and more elastic cavity and by flattening the hemisphere of the cup in the dome area. In this study, without exception, the Fitmore cup with fins was used.

A straight collarless double-tapered titanium stem (CLS Spotorno stem; Zimmer, Winterthur, Switzerland) was implanted without cement in all patients with use of the press-fit technique described by Spotorno et al. [13].

Table 1 Patient demographics and distribution of hips

\begin{tabular}{llll}
\hline Demographics & Male & Female & Total/mean (range) \\
\hline Age, mean (range) & $48(25-60)$ & $51(31-60)$ & $49(25-60)$ \\
$\begin{array}{l}\text { Hips, no. (\%) } \\
\begin{array}{c}\text { Body mass index } \\
\left(\mathrm{kg} / \mathrm{m}^{2}\right), \text { mean (range) }\end{array}\end{array}$ & $27(56 \%)$ & $39(44 \%)$ & 89 \\
Right:left & $18: 32$ & $28(20-39)$ & $28(18-42)$ \\
\hline
\end{tabular}

Table 2 Patient diagnoses

\begin{tabular}{ll}
\hline Diagnoses & Number of hips (\%) \\
\hline Osteoarthritis & $46(52 \%)$ \\
Avascular necrosis & $18(20 \%)$ \\
CDH & $11(12 \%)$ \\
Post-traumatic OA & $3(3 \%)$ \\
Rheumatoid arthritis & $3(3 \%)$ \\
Neck fracture & $1(1 \%)$ \\
Others & $7(8 \%)$ \\
\hline
\end{tabular}

The bearing surfaces used were either a 28-mm Metasul (Zimmer, Winterthur, Switzerland), forged, high-carbide ([C], $0.2-0.25 \%$ ) CoCr alloy metal-on-metal (63 hips) or a $28-\mathrm{mm}$ Al2O3 ceramic head (Biolox forte; CeramTec, Plochingen, Germany) articulating with conventional UHMWPolyethylene (Sulene; Zimmer, Winterthur, Switzerland) ceramic-on-polyethylene (25 hips). This conventional UHMW-PE is made from compression-molded, calcium stearate free GUR 1020 resin and sterilized by gamma irradiation at a dose of minimum $25 \mathrm{kGy}$ in a nitrogen environment. In one hip, a 22-mm metal-on-polyethylene articulation was used.

Either a modified Watson-Jones or a transgluteal Bauer approach to the hip was used with the patient in the supine position. Postoperatively, partial weight-bearing for six weeks was recommended. Routine prophylaxis for the prevention of heterotopic ossification was diclofenac $50 \mathrm{mg}$ twice per day for three weeks. Intravenous thirdgeneration cephalosporin (1.5 g cefuroxime) was administered peri-operatively. Anticoagulation therapy consisted of low-molecular weight heparin (enoxaparin) administered
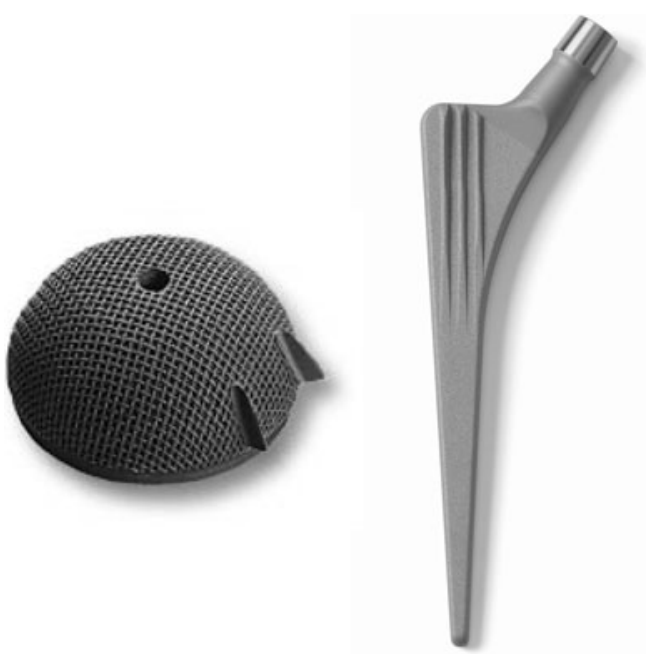

Fig. 1 Photograph showing the Fitmore acetabular component with grit-blasted titanium wire mesh and the CLS Spotorno stem 
subcutaneously the day before surgery and continued for six weeks postoperatively.

The Harris hip score (HHS) [14] was used to determine the functional level pre-operatively and at the most recent follow-up. Patient activity levels were graded according to Devane et al. [15].

For radiographic evaluation, standard pelvis anteroposterior (AP) and lateral radiographs of the hip were taken. The inclination, anteversion [16], horizontal and vertical positions of the acetabular component were determined, taking the inter-teardrop line as a fixed landmark, as described by Massin et al. [17]. The distribution of radiolucent gaps or osteolysis at the acetabular bone-prosthesis interface was recorded using the three zones described by DeLee and Charnley [18]. Osteolysis was defined as a lucent zone devoid of trabecular bone and usually with a sclerotic border and classified as minor osteolysis $\left(\leq 1.5 \mathrm{~cm}^{2}\right)$ or major osteolysis $\left(>1.5 \mathrm{~cm}^{2}\right)[8,12,19]$.

Radiolucent lines or osteolysis at the femoral boneprosthesis interface was evaluated using the zones described by Gruen et al. [20]. Femoral osteopenia due to stress shielding and femoral component fixation were graded according to the criteria described by Engh et al. [21]. Heterotopic ossification was graded according to Brooker et al. [22].

The reconstructed femoral offset was measured as the distance from the centre of rotation of the femoral head to the long axis of the femoral shaft. The native femoral offset was measured on the disease-free contra-lateral hip in patients without contralateral hip replacement or on preoperative radiographs.

In hips with ceramic-on-polyethylene articulation, linear wear was measured by one blinded observer on standard anteroposterior supine digital radiographs (5-MPix resolution) determining femoral head penetration in the single image technique using the Roman V 1.70 software (Institute of Orthopaedics, Oswestry, UK) as described by Geerdink et al. [23]. Since the Fitmore cup has an eccentric biradial design with a hemispherical periphery, the technique had to be adapted by finding the circles that best fit the hemispherical periphery of the cup to accurately determine the cup centre and the prosthetic femoral head. For the interobserver repeatability, the mean difference between the two wear measurements was $-0.01 \mathrm{~mm} /$ year ( $95 \% \mathrm{CI},-0.1$ to 0.08 ), and for the intra-observer repeatability the mean difference was $0.02 \mathrm{~mm}(95 \% \mathrm{CI},-0.06$ to 0.09$)$.

\section{Statistical analysis}

Kaplan-Meier survivorship analyses were performed with the use of several end points: revision for aseptic loosening, revision for any reason, and a re-operation on the hip for any cause (e.g., loosening of either one or both of the components, osteolysis, liner exchange, infection, periprosthetic fracture, or dislocation) were used as the endpoints. Revision was defined as "an operation that involved removal and/or replacement of one or more components of a joint replacement"; re-operation means all forms of surgery after total hip arthroplasty. Acetabular revision was further subdivided into "major", involving removal and/or replacement of the acetabular metal shell, and "minor", which did not involve the removal and/or replacement of the shell, such as an exchange of liner. Differences in survival rates between different groups of patients were tested for statistical significance using the two-sided log-rank test. Continuous variables were compared with the use of a two-sided Student'st- test. We considered $\mathrm{p}$-values of $<0.05$ to be significant. SPSS $^{\circledR}$ version 17.0 (SPSS Inc, Chicago, IL) and Graphpad Prism ${ }^{\circledR}$ version 5.0 (Graphpad Software, San Diego, CA) were used to record and analyse the collected data.

\section{Results}

\section{Sample}

At a minimum of ten years postoperatively, six patients (six hips) had died without a revision prior to death for reasons unrelated to the surgery; the mean time between operation and death was 6.6 years (range, 0.6-11.3 years). Two patients (two hips) were lost to follow-up (both patients had moved to a foreign country and could not be followed). In five hips (five patients) a revision was performed (Fig. 2). The remaining 76 hips in 75 patients were available for review at a mean follow-up of 12.4 years (range, 10.314.8 years). Sixty-three patients (64 hips) had both clinical and radiographic evaluations, 12 patients (12 hips) had only a clinical evaluation performed by telephone (as they were unwilling or unable to have radiographs made).

\section{Revisions}

Five out of 89 total hip arthroplasties (6\%) have been revised. Mean time to revision was 8.5 years (range, 5.89.9 years). In two hips $(2 \%)$ an isolated revision of the modular acetabular liner was performed; in one hip, the metal-on-metal bearing was changed to a metal-onpolyethylene articulation for unexplained pain after 8.2 years. In another hip, the bearing was revised for recurrent late dislocation after 9.9 years. No revision was performed for accelerated wear. In two hips $(2 \%)$, the femoral and the acetabular component were revised; in one hip, the stem and the shell were removed for deep infection 9.4 years after the initial operation. Another hip had a femoral revision for peri-prosthetic femoral fracture after 


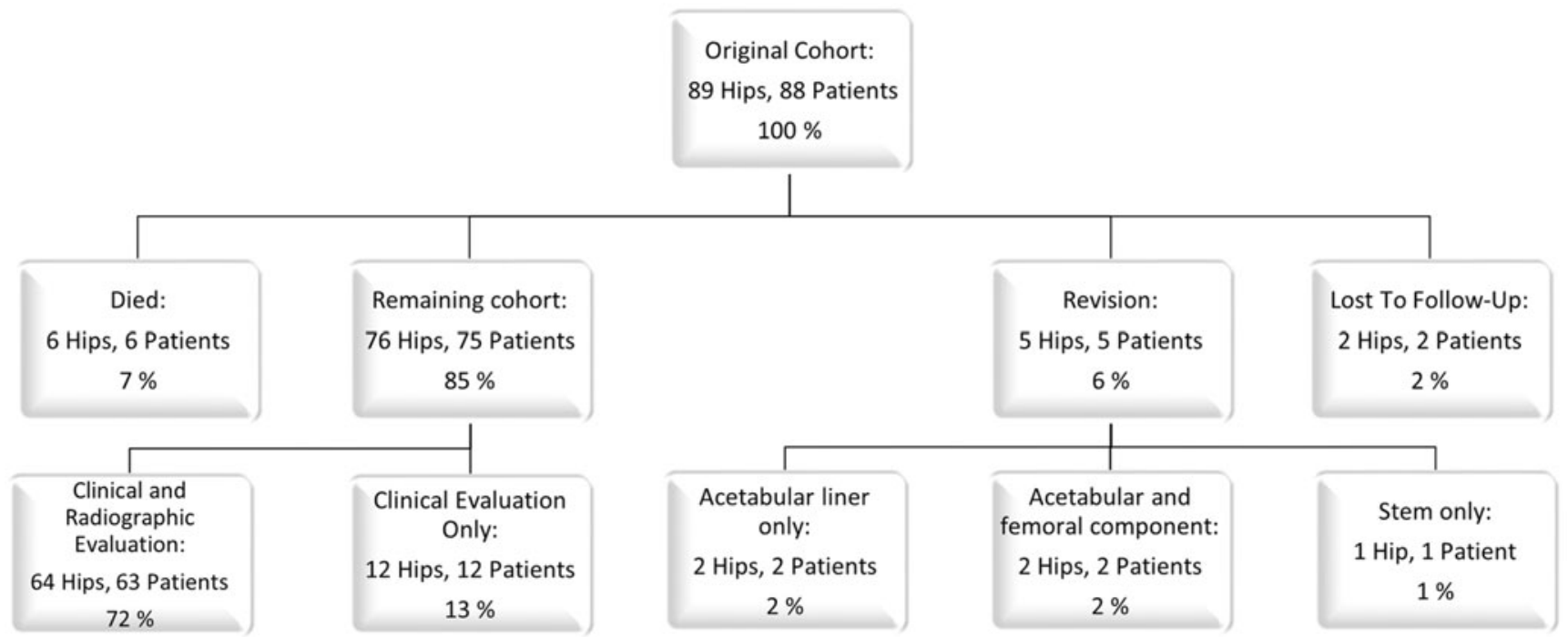

Fig. 2 Patient status at most recent follow-up

9.2 years; the acetabular component was revised at the time of stem revision although it was well fixed intra-operatively.

An isolated revision of the femoral component was performed in one hip (1\%) for aseptic loosening after 5.8 years. In this case, the femoral component had been primarily undersized and subsided subsequently. There was no revision for aseptic loosening of the acetabular shell.

\section{Impending revisions}

One hip with a ceramic-on-polyethylene bearing showed significant wear of about $50 \%$ of the liner; in this case liner exchange was recommended, but the patient refused the operative revision. We recommended annual reassessments to observe progression of wear and development of osteolysis. There were no other impending revisions or re-operations at the time of most recent follow-up.

\section{Re-operations}

One hip required surgical resection for symptomatic heterotopic ossification 7.5 years after initial operation. Another patient, who already had a liner revision for recurrent dislocation at 9.9 years (see "Revisions"), suffered a periprosthetic femoral fracture after trauma and was treated with open reduction and internal fixation at 11.7 years; all components were well fixed despite fracture and not revised in this case.

\section{Complications}

Intra-operative complications occurred in six hips (7\%) and were all related to a proximal femoral fracture during insertion of the femoral component. Four fractures were stabilized with cable wires only, and in one hip a longitudinal split of the proximal femur was treated with cable wires and a stem revision (cemented stem); this hip was also included in the study, but radiological evaluation and survivorship analysis was performed only for the acetabular component.

\section{Radiographic evaluation}

Radiographical examination showed that no acetabular or femoral components were loose at a minimum of ten years, and all appeared radiologically to have solid osseous ingrowth. We could not detect peri-acetabular osteolysis radiographically in any hip.

Radiolucent lines of less than $2 \mathrm{~mm}$ were present around the acetabular component in two of 64 hips (3\% of the hips with radiological review), involving DeLee-Charnley zone III in two hips and DeLee-Charnley zone I in one hip. We did not find peri-acetabular radiolucent lines greater than $2 \mathrm{~mm}$ in any hip.

The mean initial cup inclination angle was $45.7^{\circ}$ (range, $35.6-61.3^{\circ}$ ). The mean inclination angle at the time of final review was $45.9^{\circ}$ (range, 35.0-59.8 $8^{\circ}$. No significant change was found in cup inclination (paired Student $t$-test, $p=0.64$ ) and no acetabular component showed horizontal or vertical migration of more than $3 \mathrm{~mm}$ when comparing early and late postoperative radiographs. The mean cup anteversion angle was $12.7^{\circ}$ (range, $0-34.6^{\circ}$ ). The mean linear wear rate in the subgroup of hips with ceramic-on-polyethylene articulation $(n=25)$ was $0.13 \pm 0.06 \mathrm{~mm} /$ year (range, 0.03-0.24).

Radiolucent lines around the femoral component were observed in 12 of 64 hips $(18 \%$ of the hips with radiological review) and were limited to the proximal femur (Gruen zones 1 [9 hips], 2 [1 hip], 6 [2 hips] and 7 [9 hips]). No hip had distal cortical hypertrophy, third or fourth-degree stress-shielding with atrophy of the proximal 
part of the femur, pedestal formation at the tip of the prosthesis with bridging of the complete femoral canal, or subsidence $>5 \mathrm{~mm}$ comparing early and late postoperative radiographs. Heterotopic ossification was found in 17 of 64 hips $(27 \%)$ and was graded according to Brooker as grade I (11 hips), II (4 hips) and III (2 hips).

The mean native hip offset was $36.6 \mathrm{~mm}$ (range, 20.459.1 ) and the mean reconstructed femoral offset was $34.4 \mathrm{~mm}$ (range, 18.5-53.3). There was a statistically significant difference between native and reconstructed femoral offset (paired Student $t$-test, $p=0.02$ ).

\section{Clinical evaluation}

The HHS and the Devane activity score improved from a mean of 45 points preoperatively to a mean of 91 points at last follow-up (paired Student $t$-test, $p<0.001$ ) and from 2.6 to 3.2 points (paired Student t-test, $p=0.01$ ), respectively. At the latest follow-up, one patient (one hip; $1 \%$ of the unrevised living cohort) had a poor result (HHS $<70$ points). In this case, an intra-operative fracture of the greater trochanter was fixed with tension band wiring. At last follow-up, all components were well fixed, but the patient complained about pain in the hip (VAS 6/10; HHS 46 points). The mean HHS of the 12 patients who had no radiological follow-up was 95 (range, 75-100) points.

\section{Survivorship analysis}

The Kaplan-Meier survival analysis, with the endpoint being revision of either one or both of the components for any reason, estimated the 12-year survival rate at $94 \%$ (95\% CI, 86-97\%; Fig. 3). With the endpoint being reoperation on the hip for any cause, 12-year survival was 93\% (95\% CI, 84-97\%). When the two patients lost to follow-up were considered as revised, worst case survival

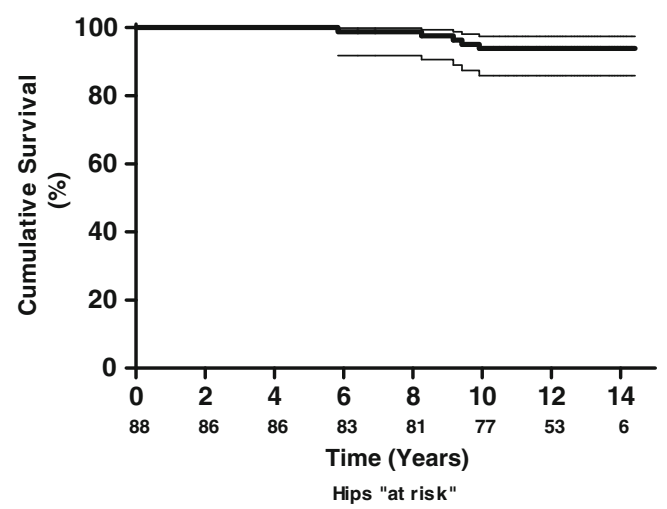

Fig. 3 Kaplan-Meier survivorship curve and 95\% confidence intervals with revision for any reason as the endpoint. Twelve-year survival was estimated at $94 \%$ (95\% CI, 86-97\%; 53 hips at risk) with the endpoint revision for any reason was $92 \%(95 \%$ CI, 83-96\%) at 12 years. With the endpoint being revision for aseptic loosening, the 12-year acetabular and femoral component survival was estimated at $100 \%$ and $99 \%(95 \%$ confidence interval, 92-100\%; Figs. 4 and 5), respectively. With the endpoint at revision for any reason, survival estimates for the acetabular and femoral components at 12 years were 95\% (95\% CI, 87-98\%) and 96\% (95\% CI, 89 99\%; Figs. 4 and 5), respectively. For hips with metal-onmetal articulation the survival rate, with revision for any reason as the endpoint, was $93 \%(95 \% \mathrm{CI}, 82-97 \%)$ at 12 years; for hips with ceramic-on-polyethylene articulation the survival rate was $100 \%$ at 12 years (Fig. 6). The difference was statistically not significant ( $\log$ rank test, $p=0.18$ ).

\section{Discussion}

Since the introduction of total hip arthroplasty in the late 1960s, the management of younger patients has been challenging and outcomes in this group of patients are controversial. Uncemented cups were introduced in the 1980s to overcome the problems of high long-term failure rates due to osteolysis and aseptic loosening as seen with cemented acetabular reconstruction, especially in young patients, despite improved cementing techniques. They are widely used in THA all over the world. While the success of uncemented acetabular components in terms of fixation is well established, problems with polyethylene wear and osteolysis often compromise the long-term survival. In their analysis based on the Norwegian Arthroplasty Register, Hallan et al. showed high revision rates for polyethylene wear, osteolysis and aseptic loosening leading to a marked decline in survivorship after ten years, while most devices

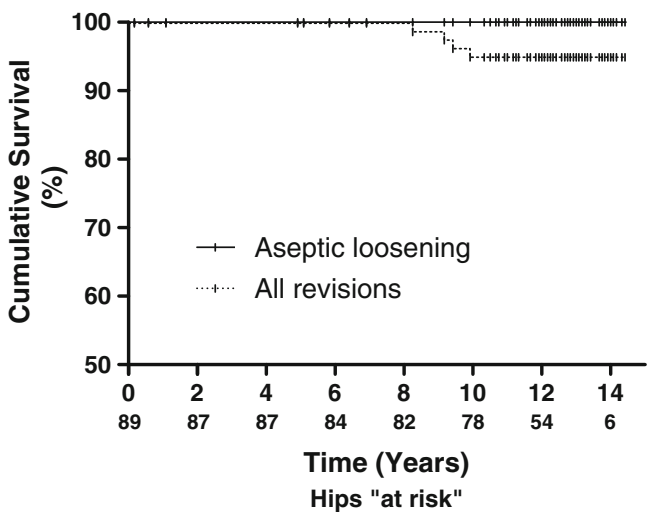

Fig. 4 Kaplan-Meier survivorship curves for the acetabular component with revision for aseptic loosening and revision for any reason (including liner revision) as the endpoint; 12-year survival was estimated at $100 \%$ and $95 \%$ (95\% CI, $87 \%-98 \%$; 54 hips at risk), respectively. Tick marks indicate censored data 


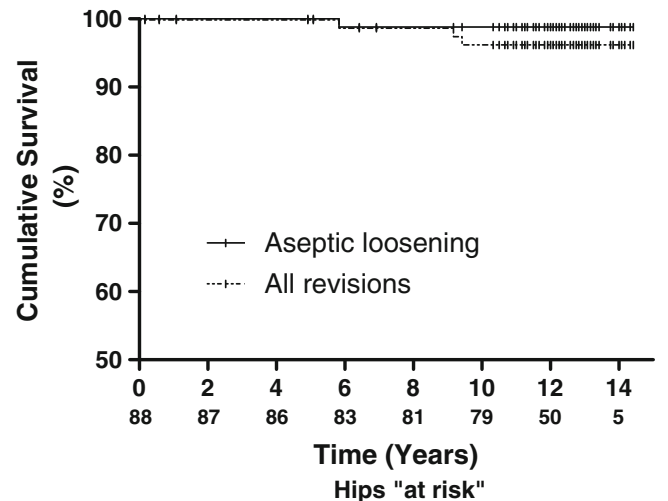

Fig. 5 Kaplan-Meier survivorship curves for the femoral component with revision for aseptic loosening and revision for any reason as the endpoint; 12-year survival was estimated at 99\% (95\% CI, 92-100\%) and $96 \%$ (95\% CI, 89-99\%; 50 hips at risk), respectively. Tick marks indicate censored data

performed well up to seven years. The authors estimated the 12-year survival for metal-backed acetabular components with conventional polyethylene between $74 \%$ and $90 \%$ when acetabular revision for any reason was used as the endpoint. They concluded that none of the components used in their study had satisfactory long-term results [6]. Similar results were documented in several non-register reports.
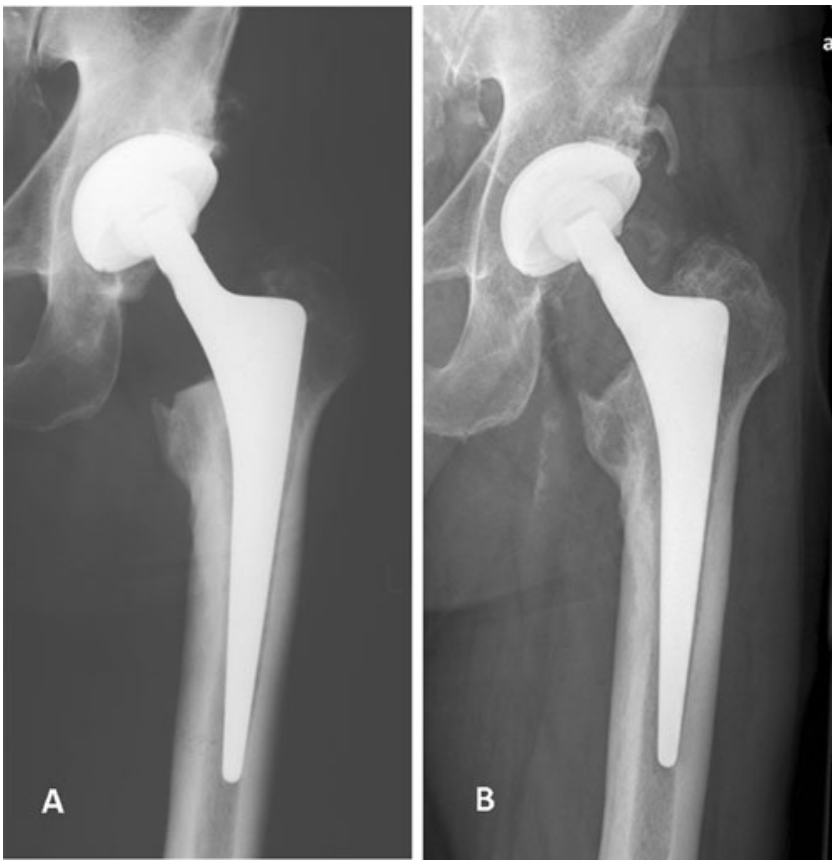

Fig. 6 Anteroposterior hip radiographs of a 51-year-old male with primary OA immediately (a) and 14 years postoperatively (b). Note the relatively low resection level at the femoral neck just above the minor trochanter. At 14 years calcar rounding and loss of medial cortical density is visible indicating second degree stress shielding according to Engh et al. [21]
The problems of osteolysis and accelerated polyethylene wear become most evident in the young and active patient $[8,9]$. In general, there is relatively little information on the survival of uncemented acetabular components in young patients in the second decade. Published reports with more than ten years of follow-up consistently show unacceptably high rates of peri-acetabular osteolysis and of re-operation for problems related to the acetabular side. In a study from the Finnish Arthroplasty Register, in patients under 55 years of age, only the Harris-Galante II cup showed a survival rate $>80 \%$ at ten years with cup revision for any reason (including liner exchange) as the endpoint (87\%); at 13 years survival declined to $78 \%$ [7]. Utting et al. reviewed the results of 70 hemispherical Harris-Galante I cups in patients under the age of 50 years. At 14 years they found a cumulative survival of $84 \%$, with acetabular revision for any reason as the endpoint; survival with impending revision as the endpoint was $55 \%$ at 14 years. Of the hips radiographically reviewed, $19 \%$ showed acetabular osteolysis [11]. Duffy et al. reported the results of 84 Harris-Galante I cups in patients 50 years or younger. At ten years cumulative survival with acetabular revision for any reason was $84.5 \%$ and osteolysis was found in $20 \%$ of the unrevised hips [24]. In a series by Della Valle et al., very acceptable results at a minimum follow-up time of 20 years were achieved with use of the Harris-Galante I acetabular component, but osteolysis was observed in more than $30 \%$ of patients who were younger than 50 years [9]. Recently, Kim et al. reported the results of a contemporary uncemented THA using the Duraloc acetabular component in combination with the uncemented Profile stem and a 22-mm CoCr head articulating with conventional ram-extruded 415 GUR polyethylene in a consecutive series of 532 hips in patients younger than 50 years old. Cumulative survival of the acetabular component at 15 years was $82 \%$ and periacetabular osteolysis was found in $20 \%$ of all hips [8].

Different factors might explain the high survival and low prevalence of peri-acetabular osteolysis in our study. First, remarkably low rates of peri-acetabular osteolysis and revision for any reason have been reported using the second generation 28-mm metal-on-metal Metasul articulation [25], also in young patients [26], though Holloway et al. reported $14 \%$ peri-acetabular osteolysis in a small cohort of 22 hips [27]. Problems with liner disassociation [28] and metal hypersensitivity/ALVAL [29] have been reported, whereas metallosis and pseudotumours seem not to be an issue with this $28-\mathrm{mm}$ polyethylene-backed bearing surface. These complications have been reported with large-head metal-on-metal articulation [30]. However, we have made a change in our clinical practice away from metal-on-metal to ceramic-on-HXLPE articulations, as the local and systemic long-term effects of metal-on-metal THA are still not fully understood [31]. 
Second, we found a comparatively low linear wear rate of $0.13 \mathrm{~mm} /$ year using a $28-\mathrm{mm}$ alumina-ceramic on UHMWPE bearing in our patients with a mean age of 49 years. Our results compare well to those reported for 28$\mathrm{mm}$ alumina-ceramic heads on UHMWPE in a retrieval study by Kim et al. $(0.11 \mathrm{~mm} / \mathrm{y})$ when uncemented metalbacked acetabular components were used in a cohort with a mean age of 45 years [32]. Although different wear rates were found in hip simulator studies, clinical and retrieval studies suggest that the penetration/wear rate is higher with metal-on-UHMWPE than ceramic-on-UHMWPE bearing [33]. Considering this, we believe ceramic-on-UHMWPE/ HXLPE articulations are a reasonable option for THA also in young and active patients.

Third, the acetabular component used in this study has a relatively thin metal back (2.5-mm thickness in all sizes) whereas most modular uncemented cups available have a thicker metal shell. Using the Trilogy shell (thickness of the metal back from $2.7 \mathrm{~mm}$ to $4.6 \mathrm{~mm}$ dependent on size) a marked decrease in peri-acetabular cancellous bone density up to $34 \%$ within one year after implantation was described [34]. A thin metal back with lower relative rigidity might allow for a higher stress transfer to cancellous periacetabular bone and therefore might reduce stress shielding. It has been hypothesized that a compromised cancellous bone structure plays an important role in the development of osteolytic lesions [34]. The flattened polar region optimizes press-fit and load transfer in the periphery of the cup, which might enhance osseointegration and sealing of the periphery of the acetabular component and limit the access of wear particles to the retro-acetabular bone. A relatively low retro-acetabular stress shielding and good peripheral osseointegration could contribute to a low rate of periacetabular osteolysis, although we have no data to support this contention.

The importance of the present report is that it represents the minimum ten-year results using contemporary uncemented implants, which are still in clinical use in a consecutive series of young and active patients with only a few patients lost to follow-up. No acetabular revision was performed for accelerated wear, osteolysis or aseptic loosening at the time of the last follow-up. We did not detect peri-acetabular osteolysis visible on plain radiographs in those hips evaluated radiographically, and all components appeared to have solid osseous ingrowth. Aseptic loosening was negligible as a failure mode in this series; we found only one aseptic stem loosening due to a primary undersized implant and no aseptic acetabular loosening in any hip.

There are important limitations of this study. First, the use of two different types of bearings makes the group heterogeneous. The study was not sufficiently powered to compare the performance of the two articulations used.
Another limitation is the evaluation of osteolysis using radiographs, as the incidence of osteolysis might be underestimated on radiographs compared to evaluation by computed tomography or magnetic resonance imaging [35]. In addition, there is a potential bias on the radiographic results as 12 hips could not be evaluated radiographically.

The survival rates and the radiological outcome after primary uncemented THA in our young and active patient group with a mean age of 49 years are encouraging into the early second decade. Our findings confirm the results of previous reports [36, 37] and compare well with those reported for the other press-fit acetabular components based on the thin cup design, like the Allofit press-fit cup [19] and the Morscher press-fit cup [38]. Peri-acetabular osteolysis and liner wear was not a major problem in this cohort at 12 years, which is noticeable when compared to the results reported for other uncemented cups in this age group. Longer follow-up is necessary to monitor if development of peri-acetabular osteolysis is just delayed into the late second decade.

Conflict of interest M.R.S. was supported by the non-commercial research fund of the "Deutsche Arthrose-Hilfe e.V.". In addition, benefits have been directed to a research fund by Zimmer Inc.

Open Access This article is distributed under the terms of the Creative Commons Attribution Noncommercial License which permits any noncommercial use, distribution, and reproduction in any medium, provided the original author(s) and source are credited.

\section{References}

1. McLaughlin JR, Lee KR (2008) Total hip arthroplasty with an uncemented tapered femoral component. J Bone Joint Surg Am 90 (6):1290-1296

2. Aldinger PR, Jung AW, Breusch SJ, Ewerbeck V, Parsch D (2009) Survival of the cementless Spotorno stem in the second decade. Clin Orthop Relat Res 467(9):2297-2304

3. Hallan G, Lie SA, Furnes O, Engesaeter LB, Vollset SE, Havelin LI (2007) Medium- and long-term performance of 11,516 uncemented primary femoral stems from the Norwegian arthroplasty register. J Bone Joint Surg Br 89(12):1574-1580

4. Vidalain JP (2011) Twenty-year results of the cementless Corail stem. Int Orthop 35(2):189-194

5. Aldinger PR, Jung AW, Pritsch M, Breusch S, Thomsen M, Ewerbeck V, Parsch D (2009) Uncemented grit-blasted straight tapered titanium stems in patients younger than fifty-five years of age. Fifteen to twenty-year results. J Bone Joint Surg Am 91 (6): $1432-1439$

6. Hallan G, Dybvik E, Furnes O, Havelin LI (2010) Metal-backed acetabular components with conventional polyethylene: a review of 9113 primary components with a follow-up of 20 years. J Bone Joint Surg Br 92(2):196-201

7. Eskelinen A, Remes V, Helenius I, Pulkkinen P, Nevalainen J, Paavolainen P (2006) Uncemented total hip arthroplasty for primary osteoarthritis in young patients: a mid-to long-term follow-up study from the Finnish Arthroplasty Register. Acta Orthop 77(1):57-70 
8. Kim YH, Kim JS, Park JW, Joo JH (2011) Periacetabular osteolysis is the problem in contemporary total hip arthroplasty in young patients. J Arthroplasty. doi:10.1016/j. arth.2011.03.022

9. Della Valle CJ, Mesko NW, Quigley L, Rosenberg AG, Jacobs JJ, Galante JO (2009) Primary total hip arthroplasty with a porouscoated acetabular component. A concise follow-up, at a minimum of twenty years, of previous reports. J Bone Joint Surg Am 91 (5):1130-1135

10. Emms NW, Stockley I, Hamer AJ, Wilkinson JM (2010) Longterm outcome of a cementless, hemispherical, press-fit acetabular component: survivorship analysis and dose-response relationship to linear polyethylene wear. J Bone Joint Surg Br 92(6):856-861

11. Utting MR, Raghuvanshi M, Amirfeyz R, Blom AW, Learmonth ID, Bannister GC (2008) The Harris-Galante porous-coated, hemispherical, polyethylene-lined acetabular component in patients under 50 years of age: a 12- to 16-year review. J Bone Joint Surg Br 90(11):1422-1427

12. Kim YH, Kim JS, Park JW, Joo JH (2011) Comparison of total hip replacement with and without cement in patients younger than 50 years of age: the results at 18 years. J Bone Joint Surg Br 93 (4):449-455

13. Spotorno L, Romagnoli S, Ivaldo N, Grappiolo G, Bibbiani E, Blaha DJ, Guen TA (1993) The CLS system. Theoretical concept and results. Acta Orthop Belg 59(Suppl 1):144-148

14. Harris WH (1969) Traumatic arthritis of the hip after dislocation and acetabular fractures: treatment by mold arthroplasty. An endresult study using a new method of result evaluation. J Bone Joint Surg Am 51(4):737-755

15. Devane PA, Horne JG, Martin K, Coldham G, Krause B (1997) Three-dimensional polyethylene wear of a press-fit titanium prosthesis. Factors influencing generation of polyethylene debris. J Arthroplasty 12(3):256-266

16. Pradhan R (1999) Planar anteversion of the acetabular cup as determined from plain anteroposterior radiographs. J Bone Joint Surg Br 81(3):431-435

17. Massin P, Schmidt L, Engh CA (1989) Evaluation of cementless acetabular component migration. An experimental study. J Arthroplasty 4(3):245-251

18. DeLee JG, Charnley J (1976) Radiological demarcation of cemented sockets in total hip replacement. Clin Orthop Relat Res 121:20-32

19. Zenz P, Stiehl JB, Knechtel H, Titzer-Hochmaier G, Schwagerl W (2009) Ten-year follow-up of the non-porous Allofit cementless acetabular component. J Bone Joint Surg Br 91(11):1443-1447

20. Gruen TA, McNeice GM, Amstutz HC (1979) "Modes of failure" of cemented stem-type femoral components: a radiographic analysis of loosening. Clin Orthop Relat Res 141:17-27

21. Engh CA, Bobyn JD, Glassman AH (1987) Porous-coated hip replacement. The factors governing bone ingrowth, stress shielding, and clinical results. J Bone Joint Surg Br 69(1):45-55

22. Brooker AF, Bowerman JW, Robinson RA, Riley LH Jr (1973) Ectopic ossification following total hip replacement. Incidence and a method of classification. J Bone Joint Surg Am 55(8):1629-1632
23. Geerdink CH, Grimm B, Vencken W, Heyligers IC, Tonino AJ (2008) The determination of linear and angular penetration of the femoral head into the acetabular component as an assessment of wear in total hip replacement: a comparison of four computerassisted methods. J Bone Joint Surg Br 90(7):839-846

24. Duffy GP, Prpa B, Rowland CM, Berry DJ (2004) Primary uncemented Harris-Galante acetabular components in patients 50 years old or younger: results at 10 to 12 years. Clin Orthop Relat Res 427:157-161

25. Dastane M, Wan Z, Deshmane P, Long WT, Dorr LD (2011) Primary hip arthroplasty with $28-\mathrm{mm}$ metasul articulation. J Arthroplasty 26(4):662-664

26. Delaunay CP, Bonnomet F, Clavert P, Laffargue P, Migaud H (2008) THA using metal-on-metal articulation in active patients younger than 50 years. Clin Orthop Relat Res 466(2):340-346

27. Holloway I, Walter WL, Zicat B, Walter WK (2009) Osteolysis with a cementless second generation metal-on-metal cup in total hip replacement. Int Orthop 33(6):1537-1542

28. Malik A, Dorr LD, Long WT (2009) Impingement as a mechanism of dissociation of a metasul metal-on-metal liner. $\mathrm{J}$ Arthroplasty 24(2):323.e13-16

29. Willert HG, Buchhorn GH, Fayyazi A, Flury R, Windler M, Koster G, Lohmann CH (2005) Metal-on-metal bearings and hypersensitivity in patients with artificial hip joints. A clinical and histomorphological study. J Bone Joint Surg Am 87(1):28-36

30. Pandit H, Glyn-Jones S, McLardy-Smith P, Gundle R, Whitwell D, Gibbons CL, Ostlere S, Athanasou N, Gill HS, Murray DW (2008) Pseudotumours associated with metal-on-metal hip resurfacings. J Bone Joint Surg Br 90(7):847-851

31. Triclot P (2011) Metal-on-metal: history, state of the art (2010). Int Orthop 35(2):201-206

32. Kim YH, Kim JS (2008) Tribological and material analyses of retrieved alumina and zirconia ceramic heads correlated with polyethylene wear after total hip replacement. J Bone Joint Surg Br 90(6):731-737

33. Jung YL, Kim SY (2010) Alumina-on-polyethylene bearing surfaces in total hip arthroplasty. Open Orthop J 4:56-60

34. Pitto RP, Bhargava A, Pandit S, Munro JT (2008) Retroacetabular stress-shielding in THA. Clin Orthop Relat Res 466(2):353-358

35. Walde TA, Weiland DE, Leung SB, Kitamura N, Sychterz CJ, Engh CA Jr, Claus AM, Potter HG, Engh CA Sr (2005) Comparison of CT, MRI, and radiographs in assessing pelvic osteolysis: a cadaveric study. Clin Orthop Relat Res 437:138-144

36. Vassan UT, Sharma S, Chowdary KP, Bhamra MS (2007) Uncemented metal-on-metal acetabular component: follow-up of 112 hips for a minimum of 5 years. Acta Orthop 78(4):470-478

37. Marchetti P, Binazzi R, Vaccari V, Girolami M, Morici F, Impallomeni C, Commessatti M, Silvello L (2005) Long-term results with cementless Fitek (or Fitmore) cups. J Arthroplasty 20 (6): $730-737$

38. Garavaglia G, Lubbeke A, Barea C, Roussos C, Peter R, Hoffmeyer P (2011) Ten-year results with the Morscher press-fit cup: an uncemented, non-modular, porous-coated cup inserted without screws. Int Orthop 35(7):957-963 